\title{
Effect of dietary lipid sources on odour-active compounds in muscle of turbot (Psetta maxima)
}

\author{
Thierry Sérot ${ }^{a \star}$, Christelle Regost $^{b}$, Carole Prost $^{a}$, Jean Robin $^{b}$, Jacqueline Arzel $^{b}$ \\ ${ }^{a}$ Ecole Nationale d'Ingénieurs des Techniques et Industries Agro-Alimentaires, Laboratoire de Biochimie \\ Industrielle Alimentaire, Rue de la Géraudière, BP 82225, F-44322 Nantes Cedex 3, France \\ ${ }^{b}$ Laboratoire de Nutrition des Poissons, Unité mixte INRA-IFREMER, Institut Français de Recherche et \\ d'Exploitation de la Mer, Centre de Brest BP 70, F-29280 Plouzané, France \\ ${ }^{*}$ Correspondence to Thierry Sérot, IFREMER, Centre de Nantes, Rue de l'lle d'Yeu, BP 21105, F-44311 Nantes \\ Cedex 3, France tserot@ifremer.fr
}

\begin{abstract}
Odour-active compounds in muscle of turbot (Psetta maxima) fed experimental diets containing fish oil (FO), soybean oil (SO) or linseed oil (LO) were investigated by a gas chromatography/olfactometry technique. Thirty-one areas associated with odours were detected in muscle extracts. Among the compounds responsible for these odours, 23 were formed by oxidation of unsaturated fatty acids. Independently of diet, (E)-2-penten-1-ol and (E)-3-hexen-1-ol contribute strongly to the odour of turbot. (E,Z)-2,6-Nonadienal, (E)-2-pentenal and (E,E)-1,3-(Z)-5-octatriene seem to contribute strongly to the odour of turbot fed diets containing high levels of $n-3$ PUFA (FO and LO groups). Hexanal and decanal show a high detection frequency in turbot fed diets containing vegetable oils. Odorous compounds which are not formed by lipid oxidation (methional, 1-acetyl pyrazine, 4-ethyl benzaldehyde and 2-acetyl-2-thiazoline) were not affected by dietary lipid sources.

Résumé
\end{abstract}

Keywords: odour-active compounds; olfactometry; turbot; vegetable oils 


\section{INTRODUCTION}

Farming of carnivorous fish requires large quantities of fish meal and fish oil. There is less and less availability of these materials, so use of diets containing vegetable materials tends to develop. Several studies have been conducted on the effects of replacement of fish oil by vegetable oils on lipid composition of rainbow trout ${ }^{1,2}$ brown trout ${ }^{3}$, Atlantic salmon ${ }^{4,5}$, charr ${ }^{6}$ and sunshine bass ${ }^{7}$. Studies carried out on turbot mainly concerned juveniles or larvae ${ }^{8,9,10}$. All these studies have shown that fatty acid muscle composition of fish was affected by dietary lipid composition. The substitution of vegetable oils for fish oil, mainly resulted in an increase in linoleic acid (18:2 n-6) concentration with soybean or corn oil ${ }^{11,3}$ and in linolenic acid (18:3 n-3) concentration with linseed oil ${ }^{8}$.

The effects of the substitution of vegetable oils to fish oil on sensory quality of fish muscle have been the subject of few studies. No significant difference was observed on the taste of brook charr fed diets added with soya oil, canola oil or menhaden oil ${ }^{6}$ and on flesh flavour of Atlantic salmon fed diets containing herring oil, soybean oil or tallow ${ }^{4}$. However, in Atlantic salmon, significant effects of soybean oil were observed on odour, taste and colour intensity ${ }^{12}$. Panellists tend to prefer flavour of fillets from trout fed a diet containing sunflower oil to flavour of fillets from trout fed a diet containing herring oil ${ }^{13}$. Rancid flavour was significantly lower in flesh of Atlantic salmon fed a diet containing low or medium levels of n-3 polyunsaturated fatty acid (PUFA) than in the one of fish fed a diet containing high levels of $n-3$ PUFA ${ }^{14}$. According to Skonberg et al (1993) ${ }^{13}$ low level of n-3 PUFA involve a decrease of oxidative rancidity and improve sensory characteristics of fillets.

Nevertheless, while odour is the principal attribute of consumer acceptance of fresh fish 15, few works have been devoted to the effects of dietary lipids on odour-active compounds of farmed fish. Previous studies mainly concerned the comparison of aroma compounds from wild and farmed fish but these results are contradictory. For instance, Suyama et al. ${ }^{16}$ have shown that volatile compounds of wild and farmed ayu were similar but the concentration was lower in farmed fish than in wild fish. However, Hirano et al ${ }^{17}$ found that there was no difference of concentration and composition of volatile compounds between wild and farmed ayu.

Many studies have proved that typical aroma of fish is related to volatile compounds arising from oxidation of n-3 PUFA by specific lipoxygenases ${ }^{15,18,19}$ and by autoxidation reactions ${ }^{20,21,22}$. Prost et al, ${ }^{23}$, using olfactometric methods, have shown that the main odour-active compounds from muscle of wild and farmed turbot resulted from oxidation of PUFA.

The aim of the present study was to determine the effects of experimental diets, containing fish oil, soybean oil or linseed oil, on odour-active compounds of turbot flesh. The fatty acid composition will be determined after extraction and gas chromatography analysis and odour-active compounds characterized by gas chromatography/olfactometry. Data are presented showing the relationships between the fatty acid composition and the perception of odour-active compounds. 


\section{MATERIAL AND METHODS}

\section{Chemicals.}

Dichloromethane (for analyses), chloroform, hexane and pentane (GC quality) were purchased from Merck (Nogent sur Marne, France). Methanol (HPLC quality) were purchased from SdS (Peypin, France). Dichloromethane (GC quality), all standard compounds, $\mathrm{BF}_{3} /$ methanol and Tricosanoic acid were purchased from Sigma-Aldrich (l’Isle d'Abeau, France).

\section{Experimental diets.}

Three experimental diets with 9\% (w/w) added lipid: fish oil (FO), soybean oil (SO) or linseed oil (LO) were formulated to be isonitrogenous (crude protein: 57\% of dry matter) and isolipidic (crude fat: $16 \%$ of dry matter). Diets were manufactured industrially by Nutreco (Aquaculture Research Center, Stavanger, Norway). Fatty acid composition of the diets is reported in Table 1.

\section{Growth study}

The growth trial was conducted on 25 turbot, (initial body weight: $579 \pm 6$ g; mean \pm sd) per diet in the experimental facilities of IFREMER (Centre de Brest) at a constant seawater temperature of $17 \pm 0.5^{\circ} \mathrm{C}$ with a salinity of $35 \%$ for a period of 13 weeks. The three experimental diets were randomly allotted to triplicate groups. Fish were fed ad libitum by hand once a day over a 90 min period.

At the end of the experiment, three fish per tank were withdrawn (the four fillets of one fish without skin were pooled and frozen at $-80^{\circ} \mathrm{C}$ ) for measurements of volatile compounds and six fish per tank were withdrawn for lipid and fatty acid analysis. These samples were frozen in liquid nitrogen and stored at $-80^{\circ} \mathrm{C}$.

\section{Total lipid extraction and fatty acid analysis}

Dorsal fillets were minced in a blender and total lipids were extracted from $6 \mathrm{~g}$ of muscle. Total lipid muscle was extracted according to Folch et al. ${ }^{24}$, chloroform being replaced by dichloromethane. Methyl esters of fatty acids were prepared as described by Morrison and Smith ${ }^{25}$ and stored at $-20^{\circ} \mathrm{C}$ until analysis.

Fatty acids were analysed by gas chromatography (GC) using a BPX 70 capillary column $(25 \mathrm{~m} \times 0.22 \mathrm{~mm}$ i.d $\times 0.25 \mu \mathrm{m}$ film thickness, SGE SARL, Villeneuve St George, France). Analyses were performed on an Autosystem Perkin-Elmer (Perkin Elmer, Courtaboeuf, France). Each extract $(0.5 \mu l)$ was injected in splitless mode. The flow rate of carrier gas (helium) was $1 \mathrm{~mL} / \mathrm{min}$. The injector and flame ionization detector (FID) temperatures were set to 220 and $260^{\circ} \mathrm{C}$ respectively. Oven temperature was raised from $50^{\circ} \mathrm{C}$ to $180^{\circ} \mathrm{C}$ at a rate of $15^{\circ} \mathrm{C} / \mathrm{min}$, maintained for $5 \mathrm{~min}$ at this temperature then raised to $220^{\circ} \mathrm{C}$ at a rate of $3^{\circ} \mathrm{C} / \mathrm{min}$. Data acquisition and handling were carried out by connecting the chromatograph to a PE Nelson computer (Perkin Elmer, Courtaboeuf, France). Individual fatty methyl esters were identified by comparison of their retention times with those of authentic standards. Fatty acid composition was expressed as percent of total identified fatty acid methyl esters. 
Table 1. Fatty acid composition of experimental diets (\% of total methyl esters).

\begin{tabular}{|c|c|c|c|}
\hline \multirow[b]{2}{*}{ Fatty acids } & \multicolumn{3}{|c|}{ Experimental diets } \\
\hline & FO & SO & $\mathrm{LO}$ \\
\hline$\sum$ Saturated & 22.5 & 18.5 & 14.3 \\
\hline 18:1n-9 & 11.9 & 17.1 & 15.0 \\
\hline 20:1n-9 & 10.2 & 3.3 & 2.8 \\
\hline 22:1n-11 & 15.1 & 4.3 & 3.3 \\
\hline$\sum$ Monounsaturated & 47.1 & 29.8 & 25.5 \\
\hline $18: 2 n-6$ & 5.2 & 35.6 & 15.5 \\
\hline $18: 3 n-6$ & 0.3 & 0.1 & 0.3 \\
\hline $20: 2 n-6$ & 0.3 & 0.2 & 0.3 \\
\hline $20: 4 n-6$ & 0.5 & 0.3 & 0.2 \\
\hline$\sum \mathrm{n}-6$ & 6.3 & 36.2 & 16.3 \\
\hline $18: 3 n-3$ & 1.3 & 4.6 & 33.3 \\
\hline $18: 4 n-3$ & 2.9 & 0.9 & 0.8 \\
\hline $20: 3 n-3$ & 0.2 & 0.1 & 0.1 \\
\hline $20: 4 n-3$ & 0.5 & 0.2 & 0.2 \\
\hline $20: 5 n-3$ & 7.9 & 3.7 & 3.6 \\
\hline $22: 5 n-3$ & 0.7 & 0.4 & 0.4 \\
\hline $22: 6 n-3$ & 10.6 & 5.6 & 5.5 \\
\hline$\sum n-3$ & 24.1 & 15.5 & 43.9 \\
\hline$n-3 / n-6$ & 3.8 & 0.4 & 2.7 \\
\hline
\end{tabular}

\section{Volatile compounds extraction and analysis Reduce pressure steam distillation}

Reduce pressure steam distillation was performed in a low-pressure distillation apparatus modified from the one designed by Forss and Holloway ${ }^{26}$ as previously described ${ }^{27}$. Approximately $250 \mathrm{~g}$ of muscle were minced in a blender. $200 \mathrm{~g}$ of minced muscle, $600 \mathrm{~mL}$ of ultrapure water and $50 \mathrm{~g}$ of $\mathrm{NaCl}$ were transferred into a 6L round bottom flask maintained at $30^{\circ} \mathrm{C}$. Distillation was continued for 4 hours under a pressure of 5 mbar until no water is present in the flask. Most of the volatile compounds were collected into a $4 \mathrm{~L}$ round bottom flask by means of condensers maintained at $1^{\circ} \mathrm{C}$. The more volatile compounds were collected in traps refrigerated with liquid nitrogen. After distillation, the contents of the $4 \mathrm{~L}$ flask and traps were pooled and extracted by $50 \mathrm{~mL}$ of freshly distilled dichloromethane at $0^{\circ} \mathrm{C}$ with magnetic stirring for $15 \mathrm{~min}$. This operation was repeated three times. After dehydration by anhydrous sodium sulphate, the organic extract was reduced to $5 \mathrm{~mL}$ in a Kuderna-Danish 
concentrator fitted with a Snyder column (Supelco ,St Quentin, France) and to $200 \mu \mathrm{l}$ under a gentle stream of nitrogen. The whole process was repeated 3 times for each turbot diet batch. The extracts were then stored at $-20^{\circ} \mathrm{C}$ in glass vials before analysis.

\section{Sensory analysis/ representativity of the extracts}

Panel. The panel was composed of 10 assessors of our department ( 6 females and 4 males; between 25 and 45 years old), previously trained in odour recognition, sensory evaluation techniques and with experience in Gas Chromatography-Olfactometry (GCO).

Sample preparation and presentation. The fillets of turbot were diced, then put in 100 $\mathrm{mL}$ black coded flasks before being presented to the panel. An aliquot of each of the volatile compounds extracts was adsorbed on a cardboard smelling strip (ref: 7140 B.P.S.I., Granger-Veyron, Lyas, France) and after 30s (time necessary for solvent evaporation) the extremities of the strips were cut and placed in dark coded flasks and presented to the panel after 30 min.

Descriptive analysis of turbot fillets and volatile extracts. The panel was asked to describe the odour of fillets or extracts, by choosing 5 attributes ${ }^{28}$.

Similarity evaluation of odour of muscle and of volatile extracts. Results of olfactometric method are more reliable if the odour of the extracts resembles closely that of the muscle of turbot submitted for extraction, therefore the odour representativeness of extracts was evaluated with a similarity test ${ }^{29}$. Panellists were asked to smell the odour of muscle and then the odour of corresponding extracts. They had to place the extracts on a $100 \mathrm{~mm}$ unstructured scale, anchored with «far from the muscle odour» on the left and «near to the muscle odour» on the right ${ }^{30}{ }^{31}$. The positions of the extracts on the scale were read as distance in millimetre from the left anchor.

Gas chromatography/mass spectrometry (GC/MS). GC/MS system consisted of an HP5890 II gas chromatograph and an HP5971 mass selective detector (Hewlett-Packard Co., Palo Alto, CA). Each extract $(1 \mu \mathrm{L})$ was injected in the splitless mode $\left(250^{\circ} \mathrm{C}\right.$ injector temperature) into a capillary column (DBWax, $30 \mathrm{~m}$ length x $0.32 \mathrm{~mm}$ i.d. x 0.5 $\mu \mathrm{m}$ film thickness, J\&W Scientific, Folsom, CA). The flow rate of carrier gas (helium) was $1 \mathrm{~mL} / \mathrm{min}$. Oven temperature was programmed from $50{ }^{\circ} \mathrm{C}$ to $180{ }^{\circ} \mathrm{C}$ at a rate of 5 ${ }^{\circ} \mathrm{C} \min ^{-1}$ and then to $250{ }^{\circ} \mathrm{C}$ at a rate of $10^{\circ} \mathrm{C} \mathrm{min}^{-1}$. Mass selective detector conditions were as follow: ion source temperature, $180^{\circ} \mathrm{C}$; ionization energy, $70 \mathrm{eV}$; mass range, 30-300 amu., electron multiplier voltage, $2100 \mathrm{~V}$ and scan rate, $2 \mathrm{~s}^{-1}$. Compound identifications were based on comparison of GC retention indices (RI) ${ }^{29}$, with those of authentic standards or with previously published literature, comparison of their mass spectra with standard MS spectra database: NBS 75K and internal library of the laboratory.

\section{Gas chromatography -Olfactometry (GC -O)}

The GC -O system consisted of 3400 Star GC (Varian Palo Alto, CA), equipped with a FID and a sniffing port supplied with humidified air at $40{ }^{\circ} \mathrm{C}$. The GC effluent was split 1:1 between the FID and sniffing port. Each extract $(4 \mu \mathrm{L})$ was injected in the splitless mode (injector temperature: $250{ }^{\circ} \mathrm{C}$ ) into a capillary column (DBWax, $30 \mathrm{~m}$ length $\mathrm{x}$ $0.32 \mathrm{~mm}$ i.d. x $0.5 \mu \mathrm{m}$ film thickness, J\&W Scientific, Folsom, CA). The flow rate of carrier gas (helium) was $1 \mathrm{~mL} / \mathrm{min}$. Oven temperature was programmed from $50{ }^{\circ} \mathrm{C}$ to $180{ }^{\circ} \mathrm{C}$ at a rate of $5{ }^{\circ} \mathrm{C} / \mathrm{min}$, then to $250{ }^{\circ} \mathrm{C}$ at a rate of $10^{\circ} \mathrm{C} \mathrm{min}^{-1}$. The FID detector was set to $280^{\circ} \mathrm{C}$. 
Frequency of detection method (FDT) The same panel of 10 judges ${ }^{33}$ previously selected for sensory analysis was used for Gas Chromatography-Olfactometry. Sniffing of the chromatogram was divided into two parts of $17 \mathrm{~min}$. Each judge participated in the sniffing of both parts, but during two distinct sessions to remain alert. The panellists were asked to assign odour properties to each detected odorant. Detection of an odour at the sniffing port by fewer than 3 of 10 assessors was considered to be noise ${ }^{23}$. The 10 individual aromagrams were summed, yielding the final aromagram (detection frequency versus RI).

\section{Statistical analysis}

Data were subjected to one-way analysis of variance to test the effects of experimental diets. In case where significant difference occurred (significance level $=0.05$ ), the Newman-Keuls test was used to compare the means. All statistical tests were performed using the STAT-ITCF software (1998) (ITCF, Paris, France).

\section{Results and discussion}

\section{Lipid and main fatty acid composition.}

Total lipid content of dorsal muscle was low (near 1\%) and no significant difference due to dietary treatments was observed. Fatty acid composition of dorsal muscle turbot is summarized in Table 2. Muscle of fish fed FO diet was mainly characterized by high levels of 22:1n-11, 20:5n-3 and 22:6 n-3 and by a ratio n-3/n-6 higher than muscle of fish fed vegetable oils. Muscle of fish fed SO diet had a high level of 18:2n-6 and a very low ratio n-3/n-6. Fatty acid composition of muscle of fish fed LO diet was characterized by a higher level of n-3 PUFA in comparison to muscle of fish fed SO and FO diets due to a high percent of 18:3n-3 supplied by linseed oil. Nevertheless, 20:5n-3 and 22:6n-3 levels of fish fed LO diet are similar to those of fish fed SO diet and lower than those of fish fed FO diet. These results show that fatty acid composition of turbot muscle reflected dietary fatty acid composition according to the previous works carried out on the substitution of vegetable oils for fish oils in diets ${ }^{3,5,8,12}$. 
Table 2. Fatty acid composition of dorsal muscle of turbot (\% of total methyl esters).

\begin{tabular}{|c|c|c|c|}
\hline \multirow[b]{2}{*}{ Fatty acids } & \multicolumn{3}{|c|}{ Experimental diets } \\
\hline & $\mathrm{FO}$ & $\mathrm{SO}$ & $\mathrm{LO}$ \\
\hline $16: 0$ & $17.6^{\mathrm{a}}$ & $16.4^{\mathrm{b}}$ & $15.2^{c}$ \\
\hline$\sum$ Saturated & $25.1^{\mathrm{a}}$ & $23.2^{\mathrm{b}}$ & $22.2^{\mathrm{c}}$ \\
\hline $18: 1 n-9$ & $11.8^{\mathrm{c}}$ & $14.1^{\mathrm{a}}$ & $13.2^{\mathrm{b}}$ \\
\hline 20:1n-9 & $6.1^{\mathrm{a}}$ & $3.0^{\mathrm{b}}$ & $2.7^{\mathrm{b}}$ \\
\hline 22:1n-11 & $6.1^{\mathrm{a}}$ & $2.6^{\mathrm{b}}$ & $2.2^{\mathrm{b}}$ \\
\hline$\sum$ Monounsaturated & $32.9^{\mathrm{a}}$ & $25.4^{\mathrm{b}}$ & $23.6^{\mathrm{c}}$ \\
\hline $18: 2 n-6$ & $5.2^{c}$ & $21.6^{\mathrm{a}}$ & $11.4^{\mathrm{b}}$ \\
\hline $20: 2 n-6$ & $0.4^{\mathrm{c}}$ & $1.3^{\mathrm{a}}$ & $0.7^{\mathrm{b}}$ \\
\hline $20: 4 n-6$ & $1.4^{\mathrm{a}}$ & $1.2^{\mathrm{b}}$ & $1.2^{\mathrm{b}}$ \\
\hline$\sum$ n-6 PUFA & $7.5^{\mathrm{c}}$ & $24.3^{\mathrm{a}}$ & $13.7^{\mathrm{b}}$ \\
\hline $18: 3 n-3$ & $0.9^{c}$ & $2.1^{\mathrm{b}}$ & $13.3^{\mathrm{a}}$ \\
\hline $18: 4 n-3$ & $1.4^{\mathrm{a}}$ & $0.7^{\mathrm{b}}$ & $0.7^{\mathrm{b}}$ \\
\hline $20: 3 n-3$ & $0.1^{\mathrm{c}}$ & $0.3^{\mathrm{b}}$ & $1.5^{\mathrm{a}}$ \\
\hline $20: 4 n-3$ & $0.7^{\mathrm{a}}$ & $0.4^{\mathrm{b}}$ & $0.4^{\mathrm{b}}$ \\
\hline $20: 5 n-3$ & $8.4^{\mathrm{a}}$ & $5.3^{\mathrm{b}}$ & $5.3^{b}$ \\
\hline $22: 5 n-3$ & $2.3^{\mathrm{a}}$ & $1.7^{\mathrm{b}}$ & $1.7^{\mathrm{b}}$ \\
\hline $22: 6 n-3$ & $20.7^{\mathrm{a}}$ & $16.7^{\mathrm{b}}$ & $17.6^{\mathrm{b}}$ \\
\hline$\sum$ n-3 PUFA & $34.5^{\mathrm{b}}$ & $27.1^{\mathrm{c}}$ & $40.5^{\mathrm{a}}$ \\
\hline$n-3 / n-6$ & $4.6^{\mathrm{a}}$ & $1.1^{\mathrm{c}}$ & $3.0^{\mathrm{b}}$ \\
\hline
\end{tabular}

Values in the same row with different superscripts are significantly different $(\mathrm{p}<0.05)$.

\section{Representativeness of the extracts}

The panellists principally described the odour of turbot muscle as a fatty fish note whatever the treatment (Table 3), even though the lipid content of turbot muscle was very low. The grass and hay notes were also suggested by at least 4 judges to characterize the odour of flesh. The descriptor «cooked fish» was only used to describe the odour of turbot fed FO diet, while a fresh fish note was used to describe the odour of turbot fed LO and SO diets (6 judges). Odour of turbot muscle was characterized by a milky note by a low percentage of panellists. Attributes used by panellists to describe the odour of the associated extract were relatively similar. In effect, fresh fish and haylike notes were used by a significant percentage of panellists, to characterize the volatile extracts. Fatty fish note that mainly characterized extracts FO and LO could perhaps be compared with the rancid note observed by Skonberg et al ${ }^{13}$ in flesh of salmonid fed diet with high level of n-3 PUFA. 
On the $100 \mathrm{~mm}$ scale the FO, SO, and LO extracts were situated at $61 \mathrm{~mm}\left(\sigma_{\mathrm{n}-1}=12\right)$, $56 \mathrm{~mm}\left(\sigma_{\mathrm{n}-1}=8\right)$ and $58 \mathrm{~mm}\left(\sigma_{\mathrm{n}-1}=11\right)$ respectively from left anchor. These results show the good relationship between the odour properties of muscle and corresponding extracts 29, 31 and justifies the determination of odour-active compounds by olfactometry analyses.

Table 3. Descriptive analysis of turbot muscle and corresponding extracts.

\begin{tabular}{llll}
\hline \multicolumn{1}{c}{ FO } & \multicolumn{1}{c}{ Attributes } \\
\hline Muscle & \multicolumn{1}{c}{ SO } & \multicolumn{1}{c}{ LO } \\
\hline & Cooked fish (6) & Fresh fish (6) & Fatty fish (6) \\
& Fatty fish (5) & Fatty fish (6) & Fresh fish (6) \\
& Hay, grass (4) & Shellfish (5), & Grass (5) \\
& Pungent (4) & Crustacean (4) & Shellfish (4) \\
& Alga (3) & Milky, buttery (3) & Milky (2) \\
& Boiled milk (3) & Hay, grass (3) & \\
Fresh fish (3) & & \\
& & & \\
Fresh fish (5) & Fresh fish (5) & Fresh fish (5) \\
& Fatty fish (4) & Hay (4) & Fatty fish (4) \\
Grass, hay (4) & Fatty fish (2) & Cooked fish (3) \\
& Cooked fish (3) & Crustacean (2) & Crustacean (3) \\
& Crustacean (3) & & \\
Shellfish (2) & &
\end{tabular}

Show in parenthesis is the number of judges who used each attribute to characterise the odour of fish or extract.

\section{Olfactometry analysis}

The results of olfactometry analysis show that 31 odorous compounds were perceived in at least one of the three extracts and 23 were identified (Table 4). Eighteen odorous compounds were significantly perceived in FO extract. Seventeen odorous compounds were detected by panellists in SO extract and 25 in LO extract. Among the 23 identified odour-active compounds perceived by the panellists, 19 resulted from unsaturated fatty acid oxidation (chemical or enzymatic) ${ }^{18,34}$ particularly aldehydes and alcohols. Aldehydes are probably the most interesting of the lipid-derived volatiles, since they have low odour thresholds ${ }^{35}$ and are known to contribute to the odour of fish ${ }^{18}$. But the most perceived volatiles in the three extracts are two unsaturated alcohols: $(E)-2-$ penten-1-ol and (E)-2-hexen-1-ol. (E)-2-penten-1-ol, perceived by 7,8,6 judges in extracts of fish fed FO, SO and LO respectively, was described with a strong mushroom-like odour. This compound has been previously reported as one of the most odorous in mussel ${ }^{36}$ and in clams ${ }^{37}$. Prost et al ${ }^{23}$ showed that (E)-2-penten-1-ol partially contributed to the aroma of farmed turbot. (E)-2-hexen-1-ol was perceived by 6, 7, 6 judges in extract of fish fed FO, SO and LO respectively and exhibits a green and moss-like odour. These two compounds are produced by oxidation of n-3 PUFA ${ }^{34,38}$. 
Table 4. Odour-active compounds in turbot muscle

\begin{tabular}{|c|c|c|c|c|c|c|c|}
\hline Peak & $\mathrm{RI}^{\mathrm{a}}$ & Compounds & $\begin{array}{l}\text { Methods of } \\
\text { identification }\end{array}$ & $\underset{\mathrm{b}}{\text { Odour description }}$ & $\begin{array}{r}\text { Frequ } \\
\text { nu }\end{array}$ & cy of & $\begin{array}{l}\text { ection } \\
\text { ges }\end{array}$ \\
\hline & & & & & $\mathrm{FO}$ & $\mathrm{SO}$ & $\mathrm{LO}$ \\
\hline 1 & 1034 & 1-propanol & MS, RI, standard & plastic & 3 & (1) & (1) \\
\hline 2 & 1067 & 2,3-pentanedione & $\begin{array}{l}\text { MS, RI, odour }{ }^{\mathrm{c}, \mathrm{d}} \text {, } \\
\text { standard }\end{array}$ & butter & 3 & (2) & (1) \\
\hline 3 & 1080 & hexanal & $\begin{array}{l}\text { MS, RI, odour }{ }^{\mathrm{c}, \mathrm{d}} \text {, } \\
\text { standard }\end{array}$ & cut grass & (1) & 4 & 4 \\
\hline 4 & 1096 & $(E, E)-1,3-(Z)-5$-octatriene & MS, RI & cheese, plastic & 7 & (2) & 6 \\
\hline 5 & 1107 & unidentified & & green & $(2)$ & 6 & 8 \\
\hline 6 & 1137 & (E)-2-pentenal & MS, RI, standard & grass & 7 & (1) & 6 \\
\hline 7 & 1157 & heptanone & MS, RI, standard & grass & (1) & 4 & (1) \\
\hline 8 & 1184 & unidentified & & rotten & 3 & (2) & (1) \\
\hline 9 & 1198 & heptanal & MS, RI, standard & grass & (1) & 4 & (2) \\
\hline 10 & 1238 & (E)-2-hexenal & MS, RI, standard & moss & (2) & (1) & 4 \\
\hline 11 & 1247 & unidentified & & green & 5 & 5 & (2) \\
\hline 12 & 1257 & (Z)-4-heptenal & MS, RI, standard & cooked fish & (1) & (1) & 3 \\
\hline 13 & 1296 & octanal & $\begin{array}{l}\text { MS, RI, odour }{ }^{c, d} \\
\text { standard }\end{array}$ & orange, citrus fruit & 5 & 5 & 3 \\
\hline 14 & 1305 & (E)-2-penten-1-ol & $\begin{array}{l}\text { MS, RI, odour }{ }^{\mathrm{c}} \text {, } \\
\text { standard }\end{array}$ & mushroom & 7 & 8 & 6 \\
\hline 15 & 1315 & unidentified & & earthy & (1) & (1) & 3 \\
\hline 16 & 1339 & (E)-2-heptenal & MS, RI, standard & roasted, fatty & 3 & 3 & 3 \\
\hline 17 & 1379 & (E)-2-hexen-1-ol & MS, RI, standard & green, moss & 6 & 7 & 6 \\
\hline 18 & 1460 & methional & $\begin{array}{l}\text { MS, RI odour }{ }^{\mathrm{c}, \mathrm{d}} \text {, } \\
\text { standard }\end{array}$ & boiled potatoes & 6 & 5 & 5 \\
\hline 19 & 1488 & $(Z, Z)-1,5$-octadien-3-ol & MS, RI & moss, mushroom & (1) & 5 & 5 \\
\hline 20 & 1510 & decanal & MS, RI, standard & fresh, plastic & (2) & 3 & 4 \\
\hline 21 & 1537 & 2-nonanol & MS, RI, standard & fruity, orange & 4 & (2) & 3 \\
\hline 22 & 1549 & (E)-2-nonenal & MS, RI, standard & moisture, earthy & (1) & (1) & 3 \\
\hline 23 & 1582 & (E,Z)-2,6-nonadienal & MS, RI odour & cucumber & 7 & 3 & 5 \\
\hline 24 & 1615 & 2-undécanone & MS, RI, standard & flower, fruity & (1) & (1) & 3 \\
\hline 25 & 1656 & 1-acétyl pyrazine & MS, RI, odour ${ }^{\mathrm{d}}$ & grilled, nutty & 6 & 5 & 6 \\
\hline 26 & 1728 & 4-éthyl-benzaldéhyde & $\begin{array}{l}\text { MS, RI, odour }{ }^{\mathrm{c}, \mathrm{d}} \\
\text { standard }\end{array}$ & $\begin{array}{l}\text { minty, anisy, } \\
\text { green }\end{array}$ & 6 & 6 & 6 \\
\hline 27 & 1763 & 2-acétyl-2-thiazoline & MS, RI, odour ${ }^{\mathrm{e}}$ & hazel nut, grilled & 5 & 3 & 6 \\
\hline 28 & 1813 & unidentified & & $\begin{array}{l}\text { citrus fruit, } \\
\text { cucumber }\end{array}$ & $(2)$ & (2) & 4 \\
\hline 29 & 1826 & unidentified & & grilled, & 5 & 4 & 3 \\
\hline 30 & 1898 & unidentified & & potato & 6 & 3 & 3 \\
\hline 31 & 1960 & unidentified & & rubber, alcohol & 0 & (2) & 3 \\
\hline
\end{tabular}

${ }^{a}$ Retention index on DB-Wax column. ${ }^{\mathrm{b}}$ Odour description as perceived by panellists during olfactometry. ${ }^{\mathrm{c}}$ Odour of the standard. ${ }^{\mathrm{d}}$ Furia $(1980)^{53}$. ${ }^{\mathrm{e}}$ Sekiwa et al $(1997){ }^{54} .{ }^{\mathrm{f}}$ Odour of the standard. (.) Compounds not significantly perceived by panellists. 
Some of odour-active compounds detected by panellists seem to be characteristic of some extracts. For instance, (E,Z)-2-6-nonadienal, 2-pentenal and an unsaturated hydrocarbon, $(E, E)-1,3-(Z)-5$-octatriene, were mainly pointed out in extracts of turbot fed FO and LO diets. (E,Z)-2-6-nonadienal was perceived by 7 judges in turbot fed FO diet and 5 judges in turbot fed LO diet while only 3 judges perceived it in SO diet. This compound that exhibits a strong cucumber-like odour, has been described in most seafood products. According to Milo and Grosch ${ }^{21,22}$ this compound strongly contributes to the odour of trout and cod. Hirano et al ${ }^{17}$ described it in ayu as the most important odorous compound, contributing to the cucumber odour of this fish. $(E, Z)-2-$ 6 -nonadienal has a very low detection threshold $(0.05 \mathrm{ppb}){ }^{39}$. It results from enzymatic degradation of n-3 PUFA, particularly 18:3n-3 and 22:5n-3, due to 12-lipoxygenase ${ }^{18}$. (E)-2-pentenal was significantly perceived only in fish fed FO and LO diets and was described by panellists as having a grass-like odour. It has been also reported in crayfish 40 and oysters ${ }^{41}$. (E)-2-pentenal is known to be formed either by action of 15 lipoxygenase on n-3 PUFA, mainly $18: 3 n-3$ and $22: 6 n-3{ }^{38}$ or by oxidative cleavage of 2,4,7-decatrienal, formed during n-3 PUFA oxidation ${ }^{42,43}$. The odorous area (peak 4) seems to be due to (E,E)-1,3-(Z)-5-octatriene according to mass spectrometry and retention index results. It was perceived in fish fed FO and LO by 7 and 6 judges respectively. This compound formed by oxidation of n-3 PUFA has been previously described in ayu ${ }^{17}$ and oysters ${ }^{41}$. The strong contribution of (E,Z)-2-6-nonadienal, 2pentenal and $(E, E)-1,3-(Z)-5$-octatriene to the odour of muscle of turbot fed FO and LO diets could be explained by their high n-3 PUFA concentration. Conversely, the perception of these compounds by few judges in the extracts from fillets of turbot fed SO diet could be correlated with their low level of n-3 PUFA. (E)-2-hexenal, (Z)-4heptenal, $(E)$-2-nonenal and 2-undecanone were mainly perceived in extracts from turbot fed LO diet. (E)-2-hexenal, described by a moss-like odour, was perceived by 4 judges. It is known to be mainly generated from scission of 12- and 13-hydroperoxy of linolenic acid ${ }^{38}$. (Z)-4-heptenal, generally characterized by fishy or potato-like odour, was perceived by 3 judges in turbot fed LO diet. Some authors have suggested that the accumulation of this compound in cod was undesirable ${ }^{44}$, others claimed that it might be desirable in freshly cooked crabmeat ${ }^{45}$. According to Hsieh ${ }^{46}$ the amount of (Z)-4heptenal, frequently described as oxidized fish-like flavour, tends to increase with the duration of frozen storage. It might be generated from oxidative degradation of $(E, Z)$ 2,6-nonadienal ${ }^{43}$. (E)-2-nonenal was described by a moisture-like and earthy odour by three judges. This compound, mainly formed by oxidation of n-6 PUFA, has been found to be a strong odorous compound in freshly harvested trout ${ }^{47}$. 2-undecanone, characterized by a fruity and flower-like odour, was previously reported as an odouractive compound in turbot ${ }^{23}$. A high level of 18:3n-3 could explain the more important perception of $(E)$-2-hexenal in fillets from turbots fed LO diet than in those of turbot fed SO or FO diets. The initial step of the oxidative degradation of fatty acids involves the formation of an alkyl radical from unsaturated fatty acid ${ }^{42}$. Such radicals are formed much more readily from PUFA such as 22:6 n-3, 20:4 n-6, 20:5 n-3 than from 18:2 n-6 and 18:1 n-9. Once radicals are formed, propagation of the breakdown of other fatty acid molecules occurs via a chain reaction. In high PUFA meat, autoxidation of the fatty acids was initiated more readily by the presence of higher quantities of 18:3 n-3, 20:5 n3 and 22:6 n-3 and after initial step, the subsequent chain reaction was less dependent of the unsaturated substrate ${ }^{35}$. Hence in muscle of turbot fed diet LO, the very high level of 18:3 n-3 and high level of 22:6 n-3 could favour the formation of breakdown products of $(E, Z)-2,6$-nonadienal [(Z)-4-heptenal] and of 18:2n-6 [(E)-2-nonenal]. However, the results concerning 2-undecanone are not readily interpreted. 
Hexanal and decanal were significantly perceived only in turbot fed diets with vegetable oils. Hexanal, which was perceived by 4 judges, is generally considered as an off flavour in seafood products, involved in oxidized fish flavour ${ }^{48}$. It could be used as an indicator of degradation of seafood products and meat from terrestrial animals ${ }^{49}$. This compound, that exhibits a grass-like odour, is produced by oxidation of n-6 PUFA. Results of olfactometric analysis could be explained by the occurrence of a higher level of n-6 PUFA in fillets of turbot fed diets with vegetable oils than in those of turbot fed FO diet. Decanal was perceived with a fresh and plastic-like odour. It mainly derives from oxidation of oleic acid ${ }^{38}$. Proportion of this fatty acid was actually higher in muscle of turbot fed SO and LO diets than in fillets of turbot fed FO diet. However, decanal which has not been previously reported as an odour active compound in seafood products, was only detected by 3 and 4 judges in turbot fed diet SO and LO respectively.

Heptanal was perceived with a grass-like odour by 4 judges in fillets from turbot fed SO diet. This compound has a medium odour threshold $(0.3 \mathrm{ppb}){ }^{39}$ and has previously been reported in other seafood products ${ }^{18,40}$. Heptanal is formed mainly by oxidation of n-9 monounsaturated fatty acids but it could also be formed by n-6 PUFA oxidation ${ }^{34}$. Formation of other active compounds is not closely related to PUFA oxidation. Methional, 1-acetyl- pyrazine and 2-acetyl-2-thiazoline are generally considered to be thermally generated ${ }^{50}$. However some studies show that formation of methional can be induced without a thermal process as found in the present study ${ }^{51,52}$. Some dicarbonyl compounds, occurring in wine, diacetyl, glyoxal or 2,3-pentanedione can induce Strecker reaction of amino acids. Methional could be formed from Strecker degradation of methionine induced by dicarbonyl compounds occurring during fatty acid oxidation. Methional exhibits a boiled potato-like odour and was perceived by 6 judges in turbot fed FO diet and by 5 judges in turbot fed SO and LO diets. However, the perception of 1-acetyl pyrazine and 2-acetyl-2-thiazoline, as of 4-ethyl benzaldehyde is not easily explained in the absence of a thermal process. It can be noted that the perception of these compounds seems to be independent of experimental diets.

\section{Conclusions}

The representativeness test, applied to volatile extracts of turbot fed experimental diets indicates that reduce pressure steam distillation yields extracts that are representative of the odour of turbot muscle.

Results of olfactometric analysis show that the most of odorants perceived in all extracts are formed during unsaturated fatty acid oxidation and that perception of numerous odour-active compounds depend of the diet. Whereas (E)-2-penten-1-ol and (E)-3-hexen-1-ol are perceived with the same intensity in all extracts, (E,Z)-2,6nonadienal, 2-pentenal, and $(E, E)-1,3-(Z)$-5-octatriene, generated during n-3 PUFA oxidation, seem to strongly contribute to the odour of fillets of turbot fed diets containing high level of n-3 PUFA (fish oil and linseed oil). Hexanal, which comes from n-6 PUFA oxidation and decanal which mainly results from 18:1n-9 oxidation are significantly perceived by panellists only in extracts from turbot fed diets with soybean oil or linseed oil. Furthermore, a high level of PUFA in muscle induces breakdown products of 18:1n-9, 18:2n-6 and of polyunsaturated aldehydes. In short, the data in this paper provide evidence for a close relationship between dietary lipids, fatty acid composition and aroma-active compounds of turbot muscle. 


\section{Literature Cited}

1. Reinitz GL and Yu TC, Effects of dietary lipids on growth and fatty acid composition of rainbow trout (Salmo gairdneri). Aquaculture, 35: 19-27 (1981).

2. Greene DHS, Selivonchick DP, Effects of dietary vegetable, animal and marine lipids on muscle lipid and hematology of rainbow trout (Oncorhynchus mykiss). Aquaculture 89: 165-182 (1990).

3. Arzel J, Martinez-Lopez FX, Métailler R, Stéphan G, Viau M, Gandemer G and Guillaume J, Effect of dietary lipid on growth performance and body composition of brown trout (Salmo trutta) reared in seawater. Aquaculture 123: 361-375 (1994).

4. Hardy RW, Scott TM, Harrell LW, Replacement of herring oil with menhaden oil, soybean oil, or tallow in the diets of Atlantic salmon raised in marine net-pens. Aquaculture 65: 267-277 (1987).

5. Skonberg D I, Rasco BA and Dong FM, Fatty acid composition of salmonid muscle change in response to a high oleic acid diet. J. Nutr 124: 1628-1638 (1993).

6. Guillou A, Soucy P, Khalil M and Adambounou L, Effects of dietary vegetable and marine lipid on growth, muscle fatty acid composition and organoleptic quality of flesh of brook charr (Salvelinus fontinalis). Aquaculture 136: 351-362 (1995).

7. Nematipour GR, Gatlin DM, Effects of different kinds of dietary lipids on growth and fatty acids composition of juvenile sunshine bass. Aquaculture. 114: 141-154 (1993).

8. Bell JG, Tocher DR, MacDonald FM, Sargent JR, Effects of diets rich in linoleic (18:2n-6) and $\alpha$ linonenic (18:3n-3) acids on growth, lipid class and fatty acid compositions and eicosanoid production in juvenile turbot (Scophtalmus maximus L.). Fish Physiol. Biochem. 13: 105-118 (1994).

9. Bell JG, Tocher DR, Farndale B M, McVicar AH and Sargent JR, Effects of essential fatty aciddeficient diets on growth, mortality, tissue histopathology and fatty acid compositions in juvenile turbot (Scophtalmus maximus). Fish Physiol Biochem 20: 263-277 (1999).

10. Castell JD, Bell JG, Tocher JR and Sargent JR, Effect of purified diets containing different combinations of arachidonic and docosahexaenoic acid on survival, growth and fatty acid composition of juvenile turbot. Aquaculture 128: 315-333 (1994).

11. Jahncke M, Hale MB, Gooch JA and Hopkins JS, Comparison of pond-raised and wild red drum (Scianops ocellatus) with respect to proximate composition, fatty acid profiles and sensory evaluation. J Food Sci 53: 286-287 (1988).

12. Thomassen M.S. and Rosjo C, Different fats in feed for salmon: influence on sensory parameters, growth rate and fatty acids in muscle and heart. Aquaculture 79: 129-135 (1989).

13. Skonberg D I, Rasco B A and Dong F M, Effect of feeding high monounsaturated sunflower oil diets on sensory attributes of salmonid fillets. J Aquat Food Prod Techn 2: 117-133 (1993).

14. Waagboo R, Sandnes K, Torrissen OJ, Sandvin A and Lie O, Chemical and sensory evaluation of fillets from Atlantic salmon (Salmo salar) fed three levels of n-3 polyunsaturated fatty acids at two levels of vitamin E. Food Chem 46: 361-366 (1993).

15. Lindsay R C, Fish flavors. Food Rev Int 6: 437-455 (1990).

16. Suyama M, Hirano T and Yamasaki S. Odour of Ayu and its volatile components. Bull Japan Soc Sci Fish 51: 287-294 (1985).

17. Hirano T, Zhang C H, Morishita A, Susuki T and Shirai T. Identification of volatile compounds in Ayu fish and its feeds, Nippon Suisan Gakkaish 58 : 547-557 (1992). 
18. Josephson D B, Seafood, in Volatile compounds in Foods and Beverages, Maarse, H., Ed by Marcel Dekker, INC pp 179-202 (1991a).

19. German J B and Kinsella J E, Lipid oxidation in fish tissue. Enzymatic initiation via lipoxygenase. J Agric Food Chem 33: 680-683 (1985).

20. Polvi S M, Ackman R G, Lall S P and Saunders R L, Stability of lipids and omega-3 fatty acids during frozen storage of Atlantic salmon. J Food Proces Preserv 15: 167-181 (1991).

21. Milo C and Grosch W, Detection of odour defects in boiled cod and trout by gas chromatographyolfactometry of headspace samples. J Agric Food Chem 43: 459-462 (1995).

22. Milo $\mathrm{C}$ and Grosch W, Changes in the odorants of boiled salmon and cod as affected by the storage of the raw material. J Agric Food Chem 44: 2366-2371 (1996).

23. Prost $\mathrm{C}$, Serot $\mathrm{T}$ and Demaimay $\mathrm{M}$, Identification of the most potent odorants in wild and farmed turbot. J Agric Food Chem 46: 3214-3219 (1998).

24. Folch J, Lees M, Sloane Stanley G.H, A simple method for the isolation and purification of total lipides from animal tisues. J Biol Chem 226: 497-509 (1957)

25. Morrison W R and Smith L M, Preparation of fatty acid methyl esters and dimethyl acetals from lipids with boron fluoride-methanol. J. Lipid Research 5: 600-608 (1964).

26. Forss D A and Holloway G L, Recovery of volatile compounds from butter oil. J Am Oil Chem Soc 44: 572-575 (1967).

27. Etievant $\mathrm{P} X$ and Bayonove CL, Aroma components of pomace and wine from the variety Muscat de Frontignan. J Sci Food Chem 34: 393-403 (1983).

28. Moio L, Chambellan E, Lesscaeve I, Issanchou S, Schlich P and Etievant P X, Production of representative wine extract for chemical and olfactory analysis. Ital J Food Sci 3: 265-277 (1995).

29. Etievant PX, Moio L, Guichard E, Langlois D, Leschaeve I, Schlich P and Chambellan E, Aroma extract dilution analysis (AEDA) and the representativeness of the odour of food extracts, in Trends in flavour research, ed by Maarse H and van der Heij DG. Elsevier Science B.V. pp 179-190 (1994).

30. Charles M, Martin B, Ginies C, Etievant P, Coste G and Guichard E, Potent aroma compounds of two red wine vinegars. J Agric Food Chem 48: 70-77.

31. Escudero A and Etievant P, Effect of antioxidants on the flavor characteristics and the gas chromatography/olfactometry profiles of champagne extracts. J Agric Food Chem 47: 3303-3308.

32. Van den Dool, H Kratz P D, A generalization of the retention index system including linear temperature programmed gas-liquid partition chromatography. J Chromatogr 11: 463 (1963).

33. Pollien P, Ott A Montignon F Baumgartner M Munoz-Box R and Chaintreau A, Hyphenated headspace-gas chromatography-sniffing technique: screening of impact odourants and quantitative aromagram comparisons. J Agric.Food Chem 45: 2630-2637 (1997).

34. Grosch W, Reactions of hydroperoxydes-products of low molecular weight, in Autooxidation of unsaturated lipids, Ed by Chan H. W. S. Academic Press, London, 95-139 (1987).

35. Elmore JS, Mottram DS, Enser M and Wood JD, Effect of the polyunsaturated fatty acid composition of beef muscle on the profile of aroma volatiles. J Agric Food Chem 47: 1619-1625 (1999).

36. Le Guen S Prost C and Demaimay M, Critical comparison of three olfactometric methods for the identification of the most potent odourants in cooked mussels (Mytilus edulis). J Agric Food Chem 48: 1307-1314 (2000) 
37. Tanchotikul U and Hsieh T C, Analysis of volatile flavor components in steamed rangia clam by dynamic headspace sampling and simultaneous distillation and extraction. J Food Sci 56: 327-331 (1991).

38. Hsieh R J and Kinsella J E, Oxydation of polyunsaturated fatty acids : mechanisms, products and inhibition with emphasis on fish. Adv Food Nutr Res 33: 233-341 (1989).

39. Leffingwell J C and Leffingwell D, GRAS Flavor Chemicals-Detection Threshold. Perfumer \& Flavorist 16: 1-19 (1991).

40. Tanchotikul U and Hsieh T C Y, Volatile flavor components in crayfish waste. J Food Sci 54: 15151520 (1989).

41. Josephson D B, Mechanisms for the formation of volatiles in fresh seafood flavors. Ph.D. thesis, University of Wisconsin- Madison 422 p (1987a).

42. Frankel E.N, Volatile lipid oxidation products. Prog. Lip. Res. 22: 1-33 (1982).

43. Josephson D B, Lindsay R C, Retro-aldol degradations of unsaturated aldehydes : Role in the formation of c4-heptenal from t2, c6-nonadienal in fish, oyster and other flavors. JAOCS 64: 1 132138 (1987b).

44. Mc Gill A S, Hardy R, Burt J R, Hept-cis-4-enal and its contribution to the off-flavour in cold stored cod. J Sci Food Agric 25: 1477-1489 (1974).

45. Chung H Y and Cadwallader K.R. Aroma Extract Dilution Analysis of blue crab claw meat volatiles. J Agric Food Chem 42: 2867-2870 (1994).

46. Hsieh R J, Contribution of lipoxygenase pathway to food flavours, in Lipids in food flavours, Ed by Ho C T and Hartman TG. Amer Chem Soc, Washington DC, pp 30-48 (1994).

47. Milo $\mathrm{C}$ and Grosch W, Changes in the odorants of boiled trout (Salmo fario) as affected by the storage of the raw material. J Agric Food Chem 41: 2076-2081 (1993).

48. Sahidi F and Pegg R B, Hexanal as an indicator of the flavor deterioration of meat and meat products, in Seafood chemistry proceeding technology and quality, Ed by Blakie academic and professional, Glasgow, pp 34-48 (1994).

49. St.Angelo A J, Lipid oxidation in foods. Crit Rev Food Sci Nutr 36: 175-224 (1996).

50. Le Guen S, Prost C, Demaimay M, Characterization of odorant compounds of mussels (Mytilus edulis) according to their origin using gas chromatography-olfactometry and gas chromatographymass spectrometry. J Chromatogr A 896 : 361-371 (2000)

51. Pripis-Nicolau L, de-Revel G, Bertrand A and Maujean A, Formation of flavor components by the reaction of amino acid and carbonyl compounds in mild conditions. J Agric Food Chem 48: 37613766 (2000).

52. Marchand S, de Revel G and Bertrand A, Approaches to wine aroma: Release of aroma compounds from reactions between cysteine and carbonyl compounds in wine. J Agric Food Chem 48: 48904895 ( 2000).

53 Furia T E, CRC Handbook of Food Additives $2^{\text {nd }}$ Ed by CRC Press :Boca Raton, FL, Vol II, pp 259316 (1980).

54. Sekiwa Y, Kubota K, Kobayashi A, Characteristic flavor components in the brew of cooked clam and the effect of storage on flavor formation. J Agric Food Chem 45: 826-830 (1997). 